Tourism in Analysis

DOI: http://dx.doi.org/10.11606/issn.1984-4867.v27i3p668-695

\title{
Tomei Caldo de Mocotó aí oh Fiquei Forte! Processo de desenvolvimento de recursos estratégicos em restaurante gastronômico
}

\section{I drank "caldo de mocotó" then i got strong! Strategic resources development process in gastronomic restaurant}

¡Bebi "caldo de mocotó" y me volví fuerte! Proceso de desarrollo de recursos estratégicos en un restaurante gastronómico

\author{
Viviane Santos Salazar ${ }^{1}$ \\ Walter Fernando Araújo de Moraes ${ }^{2}$ \\ Yákara Vasconcelos Pereira Leite ${ }^{3}$
}

\begin{abstract}
Resumo
Entender as origens da vantagem competitiva das empresas torna-se fundamental para sua sobrevivência no mercado. Uma das mais importantes teorias para explicar a vantagem competitiva das empresas é Resource-Based View (RBV), na qual os recursos estratégicos são a principal explicação para o desempenho superior das empresas. O objetivo do trabalho é analisar o processo de desenvolvimento e/ou aquisição desses recursos de um restaurante gastronômico brasileiro. A metodologia adotada foi um estudo de caso do Restaurante Mocotó e os dados coletados foram entrevistas, análise de documentos, vídeos e fotos. A metodologia de análise foi a análise de conteúdo com o auxílio do Atlas.ti. Os resultados apontam que os principais recursos estratégicos são cultura organizacional, rede de relacionamento e a capacidade de inovar e criar do chef de cozinha, que foram desenvolvidos internamente.

Palavras-chave: Recursos Estratégicos; Visão Baseada em Recursos; Restaurante.
\end{abstract}

\begin{abstract}
Understanding the origins of competitive advantage of enterprises is fundamental for their survival in the market. One of the most important theories to explain the competitive advantage of companies is Resource-Based View (RBV), in which the strategic resources are the main reason for the superior development of the enterprises. The objective of this paper is to analyze the development and/or acquisition of strategic resources of a Brazilian gastro-

\footnotetext{
Doutora e mestre em Administração pela Universidade Federal de Pernambuco (UFPE). Recife, Pernambuco, Brasil. E-mail: viviane salazar@yahoo.com.br

2 Pós-doutor pela University of Texas at Austin, Doutorado em Management Sciences - University of Manchester Institute of Science and Techonology, Mestrado em Engenharia de Produção pela Universidade Federal de Santa Catarina Ausutin, Texas, EUA. E-mail: walter.moraes@ufpe.br

${ }_{3}$ Doutora e Mestre em Administração pela Universidade Federal de Pernambuco (UFPE). Recife, Pernambuco, Brasil. E-mail: yakarav@gmail.com
} 
Tourism in Analysis

nomic restaurant. The methodology used was a case study of Mocotó Restaurant and data collection methods were interviews, documents analysis, videos and photos. The method of analysis was the content analysis with the help of Atlas.ti. The results show that the main strategic resources are organizational culture, social networking and the ability to innovate and to create of the chef, that were developed internally.

Keywords: Strategic Resources; Resource-Based View; Restaurant.

\section{Resumen}

Entender los orígenes de la ventaja competitiva de las empresas es fundamental para su manutención en el mercado. Una de las más importantes teorías para explanar la ventaja competitiva de las empresas es la Resource-Based View (RBV) que dice que los recursos estratégicos son la principal razón para el superior rendimiento de las empresas. El objetivo de este trabajo es hacer un análisis del proceso de desarrollo y/o de adquisición de estos en un restaurante gastronómico brasileño. Se trata de un estudio de caso en el restaurante "Mocotó", y para la recolección de datos se utilizó de entrevistas, análisis de documentación, vídeos y fotos. La metodología empelada ha sido el análisis del contenido con la ayuda del Atlas.ti. Los resultados apuntan que los principales recursos estratégicos son la cultura de la organización, red de relaciones y la capacidad de innovación y creación del nuevo chef de cocina que han sido desarrollados internamente.

Palabras clave: Recursos estratégicos; Teoría de recursos; Restaurante.

\section{Introdução}

Entender as origens da vantagem competitiva das empresas torna-se fundamental para sua sobrevivência no mercado. Uma das mais importantes teorias para explicar a vantagem competitiva das empresas é Resource-Based View (RBV), proposta por Penrose (1959)que apregoa que os recursos e capacidades heterogêneos de uma empresa são os aspectos-chave para explicar o desempenho superior das empresas (WERNERFELT; 1984; PRAHALAD; HAMEL; 1990; BARNEY; 1991; 2001; PETERAF; 1993).

Atualmente, depois de mais de vinte anos de pesquisa, há indícios suficientes para tratar a RBV como uma teoria robusta e madura que objetiva explicar o sucesso das empresas (BARNEY; WRIGHT; KETCHEN, 2001). Porém, a respeito de ter atingido essa maturidade, parte dos estudos publicados está segmentado em aspectos específicos e tem como premissa que os recursos são pré-existentes nas organizações. O processo de formação da base de recursos de uma empresa(BARNEY; 1986; DIERICKX; COOL, 1989) vem sendo negligenciado pelos 
Tourism in Analysis

pesquisadores (ALVAREZ; BUSENITZ; 2001), com isso a temática surgiu recentemente como um dos temas centrais para o avanço da teoria (MARITAN; PETERAF, 2011).

A aquisição de recursos foi proposta por Barney (1986) quando introduziu o conceito de mercado de fatores estratégicos (Strategic Factor Market - SFM). O SFM é o mercado onde os recursos necessários para a implementação das estratégias são adquiridos. $\mathrm{O}$ autor delineou um framework descrevendo as condições desse mercado que permitem às empresas obter recursos que conduzam à vantagem competitiva.

De modo complementar, Dierickx e Cool (1989) descreveram o mecanismo de acumulação interna de recursos estratégicos. A principal crítica dos autores ao framework proposto por Barney (1986) é que existem recursos não comercializáveis que são específicos de cada empresa e, portanto devem ser desenvolvidos internamente. Assim, o SFM existe apenas para os recursos que são comercializáveis. O SFM e o processo de acumulação dos recursos são modos complementares de uma empresa formar a sua base de recursos estratégicos (MARITAN; PETERAF, 2011). Ademais, as pesquisas sobre a aquisição e desenvolvimento de recursos têm se preocupado principalmente com questões como "o que" e devotado pouca atenção para as questões de "como", ou seja, as questões de processo. Assim, adotar uma abordagem de pesquisa processual auxiliará o entendimento da criação dos recursos heterogêneos (MARITAN; PETERAF, 2011) originando uma abordagem mais temporal e dinâmica para a linguagem, o pensamento e os métodos de análise estratégica (PETTIGREW, 1992).

Aliado a esse argumento, a literatura da RBV é generalista sobre os méritos dos recursos. Comumente as pesquisas falhavam em não considerar o contexto e a indústria nos quais os recursos podem ter valor para a empresa (MILLER; SHAMSIE, 1996), além de determinar o tempo e a causa do valor de um recurso (AMIT; SCHOEMAKER, 1993). Por outro lado, destaca-se que a RBV é uma das vertentes teóricas contemporâneas que vem despontando por sua relevância no campo da administração estratégica (RONDA-PUPO; GUERRAS-MARTIN, 2012). Com vistas a preencher a lacuna exposta e contribuir no avanço teórico e prático da RBV, este artigo objetiva analisar o processo de desenvolvimento e/ou aquisição de recursos estratégicos de um restaurante gastronômico brasileiro. Por restaurantes gastronômicos entende-se que são estabelecimentos que "estão associadas a um chef de cozinha de renome e a um cardápio com grande inventividade, além de normalmente apresentarem 
Tourism in Analysis

ambientes decorados de maneira muito elegante e com uma brigada de sala e cozinha muito bem treinada" (FONSECA, 2000, p.17).

Esse é um segmento do mercado de alimentação fora do lar que embora represente, no mundo, menos de $1 \%$ do número de restaurantes-estabelecimentos, tem um papel relevante para essa indústria na medida em que: dita tendências, estabelece padrões de qualidade que guiarão toda a indústria e tem papel de destaque na mídia e nas pesquisas acadêmicas por revelar a expressão cultural de uma sociedade.

Nas últimas décadas, a indústria de alimentação fora do lar no país viveu uma verdadeira revolução e passou de uma oferta de restaurantes estagnada, com cardápios pobres e sem criatividade a uma profusão de restaurantes estrelados. O cenário atual é consequência de uma transformação ocorrida entre as décadas de 1980 e 1990 quando houve uma efervescência sobre todos os aspectos que envolvem a gastronomia, incluindo a formação de profissionais em escolas nacionais, proliferação de restaurantes e programas de televisão com o tema da gastronomia, e principalmente reinvenções e resgates das culturas locais por meio de adaptações de técnicas, produtos e pratos.

Na sociedade atual há maior interesse em saber mais sobre culinária, desfrutar dos prazeres dos grandes restaurantes, "devorar" os livros de chefs, abastecer-se nos supermercados com produtos que antes eram consumidos apenas por uma elite econômica, tornando assim a gastronomia uma "mania" global. O Brasil tem despontado no cenário gastronômico mundial como um mercado interessante de restaurantes estrelados de vanguarda (ZANETI, 2012). Nos últimos anos os restaurantes e consequentemente os chefs brasileiros estão cada dia mais ganhando destaque internacional e compõem as listas dos mais famosos guias gastronômicos mundiais, a exemplo do guia britânico The Restaurants que desde 2006 vem premiando restaurantes brasileiros e em 2014 elegeu a chef brasileira Helena Rizzo como a melhor chef mulher do mundo. E do famoso guia francês Michelin que pela primeira vez, em 2015, publicou uma edição especial para o Brasil (restrito ao eixo Rio de Janeiro-São Paulo). Nesse sentido o presente artigo está norteado pelo seguinte problema de pesquisa: Como os recursos estratégicos deum restaurante gastronômico brasileiro são adquiridos e/ou se desenvolvem ao longo do tempo? 
Tourism in Analysis

\section{Referencial teórico}

\subsection{Classificação dos recursos}

ARBV apregoa que as empresas serão capazes de ter desempenho superior se possuírem recursos raros, valiosos, de difícil imitação e se forem capazes de explorar estes recursos (WERNERFELT, 1984; BARNEY, 1991; 2002). O conceito de vantagem competitiva surge como construto dominante na explicação do porquê algumas empresas apresentam desempenho superior (BRITO; VASCONCELOS, 2004).

Os recursos são todos os inputs do processo produtivo e a unidade básica de análise da RBV (GRANT, 1991). Geralmente os recursos são classificados em duas grandes categorias: tangíveis, aqueles recursos capazes de serem contabilizados nos balanços empresariais, que podem ser quantificados e avaliados com clareza; e os intangíveis, os que não podem ser observados ou quantificados de forma direta (GRANT, 1991) e o seu uso pode ser alavancado (HITT; IRELAND; HOSKINSSON, 2003).

Nessas duas grandes classes de recursos, Pike, Roos e Marr (2005) dividem os recursos tangíveis em físicos e financeiros; e os intangíveis em humanos, organizacionais e relacionais. Barney (1991) divide os recursos em: físicos, humanos, e organizacionais. Para Grant (1991) os recursos são divididos em: financeiros, físicos, humanos, organizacionais, tecnológicos e reputacionais. Os recursos por si só são incapazes de gerar vantagem competitiva sustentável. Para tal é necessário que tenham alguns atributos ou qualificações. A primeira delas é o valor que se refere ao potencial do recurso de explorar oportunidades e/ou neutralizar ameaças do ambiente (BARNEY, 1991). Outro atributo dos recursos estratégicos é a raridade (BARNEY, 1991; PETERAF, 1993). O recurso considerado raro é aquele que é escasso entre os concorrentes atuais e potenciais (BARNEY, 1991) ou que são específicos da empresa (REED; DEFILLIPPI, 1990).

A não imitabilidade se refere à desvantagem de custo que os concorrentes terão para obter os recursos estratégicos em comparação às empresas que já os possuem (BARNEY, 1991), sendo este atributo enfatizado por todos os autores investigados. Para Barney (1991), essa não imitabilidade se deve a condições históricas únicas, ambiguidade causal e complexidade social. Para Dierickx e Cool (1989), as barreiras de imitação decorrem das deseconomias por compressão de tempo, eficiência por massa de recursos, pelo 
Tourism in Analysis

inter-relacionamento entre recursos, pela ambiguidade causal e pela não erosão dos recursos. Esse conceito é similar à conceituação de durabilidade proposta por Grant (1991). Um recurso ser insubstituível significa que não deve haver outros recursos que permitam o desenvolvimento das mesmas estratégias ainda que de um modo diferente, mas que não sejam raros ou imperfeitamente imitáveis (CARNEIRO; CAVALCANTI; SILVA, 1999). Ademais os recursos para gerarem vantagem competitiva sustentável devem ser não transparentes ou difíceis de serem reconhecidos e replicáveis (GRANT, 1991; PETERAF, 1993) e não comercializável, ou seja, não podem ser adquiridos no mercado, pois devem ser desenvolvidos internamente (DIERICKX; COOL, 1989).

Por fim, Grant (1991) defende que os recursos estratégicos devem ter apropriabilidade, ou seja, a captação do valor do recurso deve ser adequada unicamente para a empresa detentora do recurso; e ter superioridade competitiva que significa que o recurso realmente é o melhor em relação aos competidores.

Parte dos estudos empíricos considera os recursos como pré-existentes à empresa (BINDER, 2006), apesar dos esforços iniciais de Barney (1986) e Dierickx e Cool (1989) de proporem modelos concorrentes para a aquisição e o desenvolvimento de recursos. O próximo tópico aborda essas duas propostas e a possibilidade de uni-las em um modelo teórico único.

\subsection{Desenvolvimento e/ou aquisição dos recursos}

O processo de formação da base de recursos de uma empresa é ainda um tema negligenciado pelos pesquisadores em estudos empíricos da RBV e na prática organizacional apesar de ter sido tratado de maneira concorrente por Barney (1986) e Dierickx e Cool (1989) ainda na década de 1980.

Barney (1986) é considerado pioneiro ao sugerir que há um mercado de recursos estratégicos no qual as empresas podem adquirir esses recursos para implementaras suas estratégias e que esses mercados são imperfeitos graças às diferenças das expectativas das empresas quanto ao valor futuro das estratégias. Ou seja, poucas empresas são informadas o suficiente para saberem que estratégias deverão gerar valor no futuro e quais são os recursos necessários para a implementação dessas estratégias. Essas empresas mais bem informadas pagarão pelos recursos um preço inferior ao seu retorno ou deixarão de adquiri-lo quando o seu preço está superestimado. 
Tourism in Analysis

Contestando os argumentos de Barney (1986), Dierickx e Cool (1989) propuseram um framework complementar ao SFM que unisse também o processo de desenvolvimento de recursos, pois segundo os autores existem recursos não comercializáveis que apenas podem ser desenvolvidos internamente a exemplo da reputação e por isso os recursos estratégicos das empresas não são os negociáveis no mercado e sim os acumulados internamente. Este é um argumento compartilhado também por Rumelt (1997) que advoga ser a base de recursos de uma empresa o resultado de um processo interno de criação fundamentada nas escolhas estratégicas do corpo gerencial, e que a heterogeneidade das empresas surge desse processo singular e histórico (BINDER, 2006).

Dierickx e Cool (1989) afirmam que as características particulares da empresa é que asseguram a impossibilidade de imitação das estratégias empresariais com maior desempenho. Essa condição de heterogeneidade é preservada graças aos chamados mecanismos de isolamento que têm relação estreita com as características intrínsecas das empresas como cultura, especificidade dos recursos, complexidade social, história, ambiguidade causal etc. Os autores defendem também que essa heterogeneidade é decorrência do processo de desenvolvimento dos recursos que tem as seguintes características: deseconomias de compressão do tempo; eficiência da massa de ativos; interconexão entre os estoques de recursos; erosão dos recursos e ambiguidade causal. Com o objetivo de desenvolver um entendimento mais completo tanto teórico quanto prático sobre a criação da posição heterogênea de recursos da empresa, Maritan e Peteraf(2011) propuseram pesquisar o SFM e o desenvolvimento interno de recursos conjuntamente. Por meio da revisão de literatura, as autoras identificaram maneiras pelas quais as empresas passam a ter recursos e capacidades valiosos: (1) investir no desenvolvimento interno dos recursos e capacidades; (2) valorizar os recursos heterogêneos; e (3) adquirir recursos externamente. Como os recursos e capacidades podem se desenvolver e mudar de importantes maneiras ao longo do tempo (HELFAT; PETERAF, 2003), é mister adotar uma perspectiva mais processual para investigar a aquisição e o desenvolvimento dos recursos. Devem-se enfocar assim tanto os processos organizacionais e gerenciais quanto a possibilidade de mapeamento de uma trajetória e padrão de aquisição e desenvolvimento de recursos ao longo do tempo de uma empresa (MARITAN; PETERAF, 2011).

Este componente histórico-temporal pode produzir um entendimento mais aprofundado na literatura acerca da administração estratégica sobre a complexa interação que acontece, ao 
Tourism in Analysis

longo do tempo, entre os recursos organizacionais e o seu ambiente competitivo (PRIEM; BUTLER, 2001) e explicar a vantagem competitiva das empresas (HELFAT; PETERAF, 2003). Assim a proposta deste trabalho é investigar o processo de formação da base de recursos de uma empresa numa perspectiva processual conforme modelo proposto na Figura 1. Independente da heterogeneidade, todas as empresas têm início com uma dotação de recursos e capacidades (MARITAN; PETERAF, 2011) que evolui ao longo do tempo. As dotações das empresas em geral são diferentes, e mesmo pequenas diferenças na fase inicial podem gerar posteriormente significativa diferença de desempenho, especialmente quando os efeitos de custo, tempo e aprendizagem são combinados (ZOTT, 2003).

Figura 1 - Modelo de processo de desenvolvimento e ou aquisição de recursos

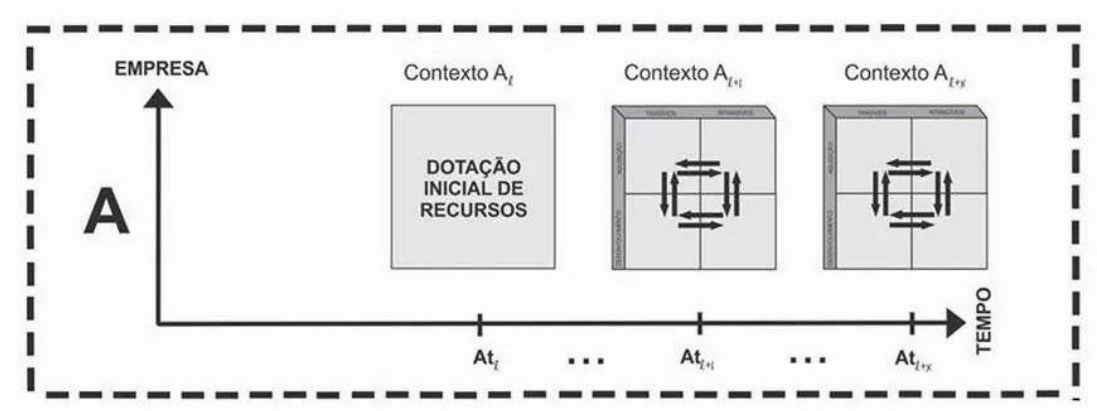

Fonte: Elaboração dos autores (2016)

Com base nessa dotação inicial, e de acordo com os diferentes contextos, o processo de construção da base de recursos da empresa pode se modificar ao longo do tempo. As empresas podem adquirir recursos tangíveis ou intangíveis no mercado ou podem desenvolvê-los internamente. O referido modelo está em consonância com a proposta de DeWit e Meyer (2004) que consideram processo, conteúdo e contexto como dimensões distintas da estratégia guiadas pelos objetivos da empresa, interagindo entre si de forma sinérgica (PETTIGREW, 1987). Contempla uma abordagem longitudinal de processo e contextual da pesquisa em organizações que pode levar a resultados da investigação mais consistentes (MILLER; MINICHILLI; CORBETTA, 2013). Ao estudar o fenômeno, a história da empresa deve ser analisada para identificar como os recursos estratégicos foram desenvolvidos ao longo do tempo. Para estudar esta proposta o campo empírico escolhido foi o dos restaurantes gastronômicos. 
Tourism in Analysis

\subsection{Restaurantes gastronômicos}

O restaurante é uma empresa onde se preparam e se vendem refeições. O primeiro restaurante surgiu na França e originalmente servia uma sopa "restauradora" para pessoas doentes. Graças à Revolução Francesa, os restaurantes cresceram em número e qualidade.

O tipo e a classificação de um estabelecimento de alimentos e bebidas pode variar de acordo com aspectos como as características do público-alvo e do mercado concorrente, o padrão de serviços a ser oferecido, além das definições relacionadas ao menu do local e os tipos, quantidades e variedades dos pratos a serem contemplados no cardápio (FERREIRA; VALDUGA; BAHL, 2016). Hoje existem inúmeros tipos de restaurantes, desde cadeias de fastfood aos chamados restaurantes gastronômicos que as pessoas frequentam não só para saciar a fome, mas também para se divertir e interagir, pois "o restaurante tornou-se um local onde se comercializa e pratica estilos experimentais de troca e diversão" (SLOAN, 2005, p.76). Graças a esse papel, na sociedade contemporânea são caracterizados como empresas que vendem um produto/serviço experiencial e onde arte, criatividade e perfeição são fatores chaves do sucesso (SURLEMONT et al., 2005; SURLEMONT; JOHNSON, 2005). Corroborando esse argumento, vários estudos apontam que além da qualidade da comida, itens como: ambiente, o tipo da comida (AUTY, 1992), o estilo do restaurante, a busca de novas experiências e questões de conveniência surgem como elementos importantes, não só no processo de escolha dos restaurantes pelos clientes (AUTY, 1992), como também são usados como critério de retorno e na comparação entre as expectativas dos clientes e o desempenho do restaurante (JOHNS; KIVELA, 2001). Essas características tornam os restaurantes bastante complexos, nos quais a oferta não se limita à comida e à bebida, sendo um sistema mais intricado e global conforme propõe Hetzel (2004). Vários autores corroboram também essa visão e vêm elaborando modelos que retratem a experiência de consumo em restaurantes gastronômicos. Com o propósito de esclarecer quais são as principais dimensões dessa experiência, foi elaborado um quadro que expõe esse entendimento (ver Quadro 1). 
Tourism in Analysis

Quadro 1 - Síntese dos principais modelos de análise da experiência em restaurantes gastronômicos

\begin{tabular}{|c|c|c|c|c|}
\hline Modelos & Autores & Bases teóricas & Principais Dimensões & Limitações \\
\hline $\begin{array}{l}\text { Sistema de oferta } \\
\text { da alta cozinha }\end{array}$ & Hetzel (2004) & $\begin{array}{l}\text { - marketing experi- } \\
\text { encial } \\
\text { - consumo simbólico }\end{array}$ & $\begin{array}{l}\text { - os pratos } \\
\text { - a arte à mesa } \\
\text { - O design e a decoração } \\
\text { - A encenação e a teatral- } \\
\text { ização } \\
\text { - A retórica do chef e sua } \\
\text { grife }\end{array}$ & $\begin{array}{l}\text { - não foi consid- } \\
\text { erada a visão do } \\
\text { consumidor para } \\
\text { a elaboração das } \\
\text { dimensões }\end{array}$ \\
\hline $\begin{array}{l}\text { A experiência } \\
\text { gastronômica dos } \\
\text { consumidores e } \\
\text { restaurantes à la } \\
\text { carte }\end{array}$ & $\begin{array}{l}\text { Hansen, Jen- } \\
\text { sen e Gustafs- } \\
\text { son (2005) }\end{array}$ & $\begin{array}{l}\text { - marketing de } \\
\text { serviço } \\
\text { - qualidade nos } \\
\text { serviços }\end{array}$ & $\begin{array}{l}\text { - produto principal } \\
\text { - interior do restaurante } \\
\text { - encontro social } \\
\text { - a companhia } \\
\text { - atmosfera do restau- } \\
\text { rante }\end{array}$ & $\begin{array}{l}\text { - não foram con- } \\
\text { sideradas as impli- } \\
\text { cações práticas do } \\
\text { modelo }\end{array}$ \\
\hline $\begin{array}{l}\text { Os aspectos do } \\
\text { modelo de uma } \\
\text { refeição: uma } \\
\text { ferramenta para } \\
\text { o desenvolvi- } \\
\text { mento do serviço } \\
\text { de refeições em } \\
\text { restaurantes }\end{array}$ & $\begin{array}{l}\text { Gustafsson et } \\
\text { al. (2006) }\end{array}$ & $\begin{array}{l}\text { - marketing de } \\
\text { serviço - aplicação } \\
\text { prática do modelo } \\
\text { anterior }\end{array}$ & $\begin{array}{l}\text { - ambiente físico } \\
\text { - encontro } \\
\text { - produto } \\
\text { - atmosfera } \\
\text { - sistema de controle } \\
\text { gerencial }\end{array}$ & \\
\hline
\end{tabular}

Fonte: Elaborado pelos autores (2016)

O primeiro modelo foi construído com o propósito de relatar a mudança da oferta dos restaurantes gastronômicos ao longo do tempo. De maneira progressiva a oferta dos restaurantes evoluiu da supremacia puramente gustativa, ou seja, da simples oferta da refeição a uma total estimulação, incluindo ainda a participação do chef de cozinha (TEIXEIRA; BARBOSA, 2008). Conforme defende Hetzel (2004) o sistema de oferta proposto por alguns restaurantes não mais se limita às preparações culinárias, mas engloba: o lugar, a arquitetura, o design, a encenação; e esse conjunto vai concorrer para criar um espaço que libertará algo extremamente único de modo a promover um fenômeno experiencial.

O modelo de Hansen, Jensen e Gustafsson (2005) considera que existem cinco dimensões que compõem a oferta do restaurante gastronômico: produto principal, o interior do restaurante, o encontro social, o ambiente social e a atmosfera. Para os autores, o produto principal do 
Tourism in Analysis

restaurante é a experiência holística, a combinação entre comidas e bebidas e o entorno que criam reações e interações sociais. Esta dimensão é composta por sensações do gosto no consumo, formas de apresentação dos pratos e bebidas e a composição do cardápio. O interior do restaurante consiste nas cores, nos utensílios usados à mesa, no mobiliário e nos outros objetos do restaurante como quadros e objetos de decoração. O encontro social é a interação entre clientes e pessoal de serviço e entre os próprios clientes. $\mathrm{O}$ ambiente social compreende as companhias com as quais se tem a refeição. E a atmosfera é composta por categorias que se referem aos sentidos e ao ambiente como iluminação, sons, temperatura, odores etc.

Por fim, o terceiro modelo, além das dimensões citadas anteriormente, abrange todo o sistema de controle gerencial que inclui os aspectos econômicos e legais, controle de custos e liderança. Conforme argumentam os autores do modelo, é o sistema gerencial que dá suporte a todos os outros. Com base nesses modelos, pode-se inferir que a oferta dos restaurantes gastronômicos é formada pelas seguintes dimensões: a figura do chef de cozinha e a sua concepção do negócio, o produto em si (os pratos e as bebidas oferecidos, o cardápio), a atmosfera, o serviço da equipe do salão (interação entre pessoal de serviço e clientes) e o sistema de gerenciamento.

Apresentado o referencial teórico, no próximo capítulo são expostos os procedimentos metodológicos para o exame do fenômeno em investigação.

\section{Procedimentos metodológicos}

Para atender ao objetivo geral deste artigo, adotou-se a perspectiva qualitativa. Dentre as abordagens possíveis, de pesquisa qualitativa, elencadas por Creswell (2007), optou-se pelo estudo de caso que envolve a investigação de um tema explorado por meio de um ou mais casos dentro de um sistema limitado e tem como características principais a descrição intensa e holística do tema pesquisado. É aplicado objetivando um entendimento profundo da situação e do seu significado (MERRIAN, 1998; CRESWELL, 2007). Ademais, permite compreender os fenômenos individuais e organizacionais, principalmente, quando os objetos são complexos e contemporâneos (YIN, 2010), como os restaurantes gastronômicos.

Com vistas a adequar a metodologia à pesquisa optou-se pelo estudo de caso qualitativo histórico de cunho descritivo que propicia investigar a empresa selecionada ao longo do 
Tourism in Analysis

tempo (MERRIAM, 1998), dado que a metodologia longitudinal, ao explorar o contexto e o processo de mudança ao longo do tempo, permite a interconectividade entre fenômenos históricos e presentes (PETTIGREW, 1990).

Para selecionar o caso estudado, o critério usado foi o proposto por Yin (2010) quando o caso é extremo ou único. O mercado de gastronomia de vanguarda foi o primeiro critério de seleção devido à: (1) sua importância econômica e seu papel de destaque no mercado de alimentação fora do lar; (2) pelo compromisso dos pesquisadores com o desenvolvimento científico da área de hospitalidade. O segundo critério foi a representatividade do caso e para isso utilizou-se a lista anual dos 50 Melhores Restaurantes da América Latina elaborada pela publicação especializada The Restaurants, edição 2013.A crítica especializada exerce um papel importante no mercado gastronômico. Por ser um gênero jornalístico opinativo sobre o trabalho de um chef ou restaurante e o seu desempenho, influencia a demanda por alimentação fora de casa, o que afeta, consequentemente, o preço e a frequência dos restaurantes (BARBOSA, 2008). Em 2013 foram listados apenas nove restaurantes brasileiros. Todos foram contatados e a escolha neste caso se deu por acessibilidade. O caso escolhido foi o restaurante Mocotó que ocupou a $16^{\text {a }}$ posição.

Em uma pesquisa pode-se utilizar uma ou mais técnicas de coleta de dados e essa escolha está relacionada às características da pesquisa, quais sejam: qualidade esperada dos dados coletados, custos da coleta ou o período pesquisado. As técnicas de coleta de dados geralmente compreendem dados verbais - entrevistas, análise documental, observação; e dados multifocais como vídeos, fotos e sons (FLICK, 2009; BAUER; GASKELL, 2002). Para este estudo foram realizadas duas visitas ao restaurante e entrevistas semiestruturadas com os proprietários, José Almeida e Rodrigo Oliveira que também é o chef, e com o gerente do estabelecimento que foram posteriormente transcritas. Rodrigo foi entrevistado duas vezes, uma em São Paulo (SP) e outra em Recife (PE) por ocasião da sua participação num evento gastronômico na capital pernambucana. Foram entrevistados também um dos jurados brasileiros da The Restaurants, o sociólogo Carlos Alberto Dória, e o presidente do júri na América Latina, Josimar Melo.

Os documentos usados na análise foram entrevistas e informações colhidas na internet e nas revistas especializadas do país (Prazeres da Mesa, Gula, Menu, Engenho, Continente Multicultural) bem como o cardápio do restaurante e todas as informações e fotos disponibilizadas no site do restaurante ${ }^{4}$. Ademais foram vistos 11 vídeos disponibilizados no

\footnotetext{
4 Disponível em: <www.mocoto.com.br>. Acesso em: 5 dez. 2016.
} 
Tourism in Analysis

Youtube que totalizaram 69 minutos e 39 segundos. Outra técnica de coleta de dados utilizada foi a observação não participante que se caracteriza como um método de coleta de dados que permite ao pesquisador avaliar detalhadamente as condições e dimensões do ambiente (PATTON, 2001).Em cada uma das visitas ao restaurante a pesquisadora passou um período (tarde) no estabelecimento e teve a oportunidade de experimentar vários pratos do cardápio, visitar as instalações do restaurante, tirar fotos e conversar com alguns funcionários.

A opção metodológica para a análise dos dados deste trabalho foi a análise de conteúdo (BARDIN,2011).O software Atlas.ti apoiou essa etapa da pesquisa. Para alcançar o rigor científico esperado na academia, a análise de dados contemplou três passos: descrição, inferência e interpretação. Os dados foram examinados de forma analítica favorecendo a realização de inferências acerca das informações com apoio do referencial teórico; por fim, receberam significação mediante interpretação da pesquisadora (BARDIN, 2011).

\section{Discussão dos resultados}

O Restaurante Mocotó, localizado na Vila Medeiros, subúrbio de São Paulo, em 2016 ocupou o $35^{\circ}$ lugar na publicação The Restaurants. Ao longo dos seus 41 anos de existência o restaurante tem acumulado vários outros prêmios que o destacam no cenário nacional e internacional. A primeira indicação a prêmio aconteceu em 2008 quando foi indicado pela revista Gula como Melhor Restaurante de Cozinha Brasileira. Ganhou também os prêmios de Melhor Restaurante Bom e Barato pela revista Veja São Paulo e o de chef revelação concedido pela Revista Prazeres da Mesa.

Desde então não apenas o restaurante, como o seu chef de cozinha, vêm ganhando mais reconhecimento da mídia especializada. Apenas em 2012 foi eleito como um dos 100 Melhores Restaurantes do Mundo pela Newsweek Magazine, como o melhor restaurante de cozinha brasileira pela revista Prazeres da Mesa e pelo jornal Folha de São Paulo, o Chef do Ano pela revista Prazeres da Mesa e o Melhor Restaurante Bom e Barato pela revista Época e pelo jornal Folha de São Paulo.

Mas o Restaurante Mocotó não tinha o propósito de ser estrelado e nem de figurar na lista de vanguarda do The Restaurants. A história dessa empresa familiar de sucesso pode ser 
Tourism in Analysis

dividida em três fases e teve início em 1973, começando com um pequeno empório, cresceu com um boteco, virou um bar, um restaurante e hoje ainda não sabe se é um restaurante com ar de boteco ou se é um boteco com ar de restaurante.

\subsection{Fase 1 - Casa do Norte (1973-1994)}

O Mocotó começou como uma pequena malharia e dentro dela um empório chamado Casa do Norte Irmãos Almeida, em 1973, na Vila Aurora, Zona Norte de São Paulo, fruto da sociedade do Sr. Zé Almeida e mais dois dos seus irmãos. Em 1974 montaram outra filial da Casa do Norte na Vila Medeiros e em 1976 uma terceira em Mandaqui. Nesse mesmo ano, aconteceu a divisão da sociedade e coube ao Sr. Zé ficar com a filial da Vila Medeiros. Essa divisão se deu apenas porque como afirma o Sr. Zé "como ali, a inscrição foi aberta no meu nome, ai eu fiquei com essa daí. Fraquinha, ai eu fiquei trabalhando no balcão: cozinheiro, lavador de prato, balconista, eu era tudo lá, porque era pequenininho, né?".

Somente em 1977 é que o que viria a se tornar a atração do restaurante, o caldo de mocotó, começaria a ser comercializado. No começo eram preparados e vendidos entre os produtos do empório conforme afirma Sr. Zé: "servia em copo americano e as pessoas se apoiavam nas prateleiras, entre os sacos de feijão e farinha".

Em 1979 aconteceu a primeira expansão, e um imóvel em frente ao Empório foi alugado. Nesse imóvel havia cerca de dez mesas, e os caldeirões de caldo de mocotó, favada, baião-de-dois e sarapatel eram disponibilizados no balcão. Percebe-se uma mudança estratégica quando o Empório perdeu espaço para a venda de comida.

Outro evento marcante dessa fase é a entrada de Rodrigo, filho mais novo do Sr. Zé, no negócio. A razão para a entrada foi para estar perto do pai, como ele relata: "comecei a trabalhar aqui aos 13 anos e o motivo principal, sem dúvida, era estar perto do meu pai, porque ele trabalhava e era muito dedicado". O amor ao pai e a sua história de vida impulsiona o chef até hoje a inovar e divulgar a comida sertaneja ${ }^{5}$.

O último evento dessa fase ocorreu em 1994 com o fechamento da Casa do Norte e a dedicação da família exclusivamente ao pequeno restaurante, nas palavras do Sr. Zé, "no dia que vendi 21 caldeirões do caldo, senti que o lado das refeições falou mais alto. O Mocotó não era mais um empório", diz Sr. Zé, que, a partir de 1994, fechou a Casa do Norte e dedicou-se apenas

\footnotetext{
5 Comida típica do sertão - sub-região do nordeste brasileiro localizado entre o agreste e o meio norte. Seu clima predominante é o semiárido, caracterizado pelos longos períodos de seca e a vegetação predominante é a caatinga.
} 
Tourism in Analysis

à cozinha. Nessa fase a estratégia adotada pelo restaurante estava baseada basicamente na qualidade do produto, o caldo de mocotó, que já atraia muitos clientes e fez o negócio da alimentação superar o de venda de produtos no empório e ter uma boa reputação entre os clientes.

\subsection{Fase 2 - É um restaurante ou um bar? (1995-2004)}

A segunda fase da empresa compreende o período de dez anos e dentre os eventos marcantes destacam-se a entrada efetiva de Rodrigo no restaurante, em 1995. Quatro anos depois, o inquieto jovem introduz algumas inovações no cardápio do pequeno bar como sucos e sobremesas. E se iniciam nessa fase as várias reformas na estrutura física - cozinha, depósito e aumento do salão, de forma emergente conforme afirma o chef:

mais uma vez era por pura intuição, porque eu não tinha experiência nenhuma no mercado e eu sentia que a gente podia fazer melhor, mais bem feito ou mais fácil e aí comecei a mirabolar coisas e planos, reformas e equipamentos até que eu tive a primeira grande oportunidade em 2001 ainda, que meu pai viajou e aí eu comecei a parte mais delicada da reforma, a primeira mexida.

Outro evento importante da fase se constituído ingresso de Rodrigo na faculdade de Gastronomia depois de desistir de outras duas graduações: "eu fui estudar engenharia ambiental, depois troquei pelo curso de gestão ambiental, até que eu larguei e fui fazer gastronomia na Anhembi Morumbi e me formei em meados de 2005". Durante a faculdade começou a formar sua rede de relacionamento com professores, como Mara Sales, e com outros chefs. Em 2004 aconteceram outros dois eventos importantes dessa fase. O imóvel vizinho é adquirido e mais uma expansão é realizada. Nesse ano, o Mocotó faz parte e vence o Festival "Comida di Buteco" com um prato de carne de sol criado por Rodrigo. A ação é apontada como um evento marcante: "teve a primeira crítica da Veja em São Paulo, foi uma das primeiras resenhas, que o Arnaldo Lorençato me ligou: 'é restaurante ou um bar?'. Não, restaurante. Não é um bar com comida de restaurante? É um restaurante com jeito de bar". Foi a partir dessa crítica que o Mocotó começou a se fazer conhecido além da Vila Medeiros e começou a chamar a atenção da crítica especializada.

Ainda nessa fase as estratégias adotadas se basearam na qualidade do produto e na hospitalidade da empresa. A hospitalidade, ou seja, o bem receber foi sempre uma característica da personalidade do Sr. Zé Almeida que está presente no modelo de negócio do Mocotó, 
Tourism in Analysis

pois conforme afirma Rodrigo: "O Mocotó sempre foi um restaurante muito mais inclusivo do que exclusivo, e meu pai sempre foi um grande anfitrião, que tem prazer em servir. Sem dúvida, eu herdei essas características dele".

Percebe-se que desde o início e especialmente nessas duas primeiras fases, o processo de formação das estratégias foi totalmente emergente. O gerente da casa, Ricardo, afirma que: "A gente planejou depois que aconteceu, porque o Mocotó não foi criado para atender essa demanda, o Mocotó não foi criado para ganhar prêmio, o Mocotó não foi criado para ser destaque da mídia".

O processo de formação das estratégias compreendeu desde a concepção das reformas físicas até construção do modelo de negócios adotado.

\subsection{Fase 3 - Tomei caldo de Mocotó e fiquei forte (2005-2013)}

A terceira e última fase do restaurante se destaca como a mais famosa e criativa. Essa fase é marcada por quatro eventos marcantes e todos estão, de alguma forma, relacionados ao filho do Sr. Zé Almeida e atual chef do Mocotó, Rodrigo Oliveira. O primeiro se refere à conclusão do curso de gastronomia e a viagem de mais de 50 dias pelo sertão brasileiro, realizada pelo chef em busca de novos produtos e para conhecer melhor a cachaça. O segundo momento, em 2008, é quando Rodrigo ganha o prêmio de Chef Revelação da revista Prazeres da Mesa (publicação gastronômica de maior circulação no país) e assim conseguiu o feito de levar os holofotes do meio gastronômico para uma cozinha nada convencional: regional, de boteco e nordestina.

Outro evento marcante é a concepção e construção do Engenho Mocotó, espaço dedicado à pesquisa que o chef mantém na Vila Medeiros. O espaço foi montado com a ajuda de vários parceiros que doaram os equipamentos e boa parte do acervo de livros. Esse espaço é utilizado pelo chef para pesquisar novos ingredientes e pratos; pelos funcionários que podem usar seus momentos de descanso para ler; pelos restaurantes da vizinhança para testarem novos equipamentos; pelos colegas chefs para treinamentos e pelos participantes do grupo de estudos C5 (Centro de Cultura Culinária Câmara Cascudo) que o chef lidera junto com o professor e sociólogo Carlos Alberto Dória.

Por fim, em 2013, o restaurante foi eleito pela publicação inglesa de vanguarda culinária The Restaurants o $16^{\circ}$ Restaurante da América Latina e o chef inaugurou junto com mais três sócios investidores, com investimentos de mais de 3 milhões de reais, o Esquina Mocotó. 
Tourism in Analysis

De certa forma a abertura do novo empreendimento, nas palavras do crítico gastronômico da Folha de São Paulo, Josimar Melo, "significa, por tabela, a preservação da casa original, o vizinho Mocotó", pois permite ao chef inovar, criar e fazer experimentações. Navisão de Rodrigo trata-se de: "uma casa que vem complementar o próprio serviço do Mocotó. Aqui a gente tem mais condições de experimentar produtos, novas maneiras de fazer [...] no Esquina o barro ainda é fresco, a gente consegue modelar com mais liberdade".

Nessa fase foram identificados tipos de estratégias seguidas pela empresa: a qualidade do produto e a hospitalidade que sempre estiveram presentes na trajetória da empresa. E mais recentemente a capacidade de contar uma história, no caso do Mocotó, a história do sertão nordestino e a estratégia de tradição e vanguarda. O chef explica que:

Fazer cozinha brasileira para mim é fazer a comida do sertão, que é o meu chão e o de minha família, é contar nossa história. De lá vem nossa riqueza, nosso entendimento e posicionamento no mundo. É o que e como servimos. É nossa paixão.

A estratégia de tradição e vanguarda é percebida na concepção dos pratos elaborados, pois apesar de manter a originalidade dos pratos, hoje no Mocotó são empregados técnicas e equipamentos modernos em preparações clássicas como a carne de sol, que é feita no sous-vide. E o torresmo que para o chef é "uma das coisas que a gente pensa aqui é nos novos clássicos. Então, por exemplo, a gente faz torresmo. A gente faz torresmo de um jeito que passa a ser a referência quando você fala de torresmo". Essa visão é corroborada pelo sociólogo Carlos Alberto Dória, que afirma que o diferencial do Mocotó é o preparo técnico moderno que o chef deu aos pratos tradicionalmente rústicos, assim revela: "Ele traz nova valorização para uma gastronomia muitas vezes ignorada".

Nessa fase, o processo de formação das estratégias apesar de ter ainda um componente emergente foi mais planejado, pois como afirma o gerente:

hoje a gente tenta antever um pouco algumas situações, mas até pela crescente do Mocotó, a gente acabou sendo muito mais reativo do que proativo. A gente não tinha tempo de planejar o próximo passo, a gente tinha que reagir ao passo anterior.

Alguns fatos corroboram o planejamento tais como as reformas físicas que foram executadas sob a supervisão de um escritório de arquitetura, o Lab. Atualmente as contas do Mocotó são 
Tourism in Analysis

auditadas por um profissional especialista que trabalha também com outros restaurantes de São Paulo para dar suporte na gestão financeira da casa.

A partir das fases identificadas no processo de formação das estratégias (MINTZBERG, 1973; 1978) do Mocotó, dos eventos marcantes e das estratégias empresariais adotadas, no próximo tópico serão identificados os recursos estratégicos da empresa e como foram desenvolvidos ao longo da história da empresa, que estão resumidos na Figura 2.

\subsection{Processo de desenvolvimento e ou aquisição dos recursos estratégicos do Restau- rante Mocotó}

A dotação inicial (Fase 1 - 1973 a 1994) dos recursos (MARITAN; PETERAF, 2011) do Mocotó era composta pelos recursos humanos, organizacionais, reputacionais e os relacionais (BARNEY, 1991;PIKE; ROOS; MARR, 2005). Nessa fase o recurso humano principal era o Sr. Zé Almeida com a sua capacidade de trabalho, sua visão empreendedora e personalidade. Na época da divisão da sociedade entre os três irmãos, a única filial que tinha o diferencial de vender o caldo de Mocotó era a da Vila Medeiros e esta foi a única empresa que prosperou (ver Quadro 2).

Quadro 2 - Análise empírica do processo de desenvolvimento e ou aquisição dos recursos

\begin{tabular}{|c|c|c|c|c|c|}
\hline Fases & $\begin{array}{c}\text { Estratégia } \\
\text { empresarial }\end{array}$ & $\begin{array}{c}\text { Processo } \\
\text { (MINTZBERG, } \\
\text { 1973; 1978) }\end{array}$ & $\begin{array}{c}\text { Recursos } \\
\text { (BARNEY, } \\
\text { 1991;PIKE; } \\
\text { ROOS; MARR, } \\
\text { 2005) }\end{array}$ & $\begin{array}{l}\text { Vantagem } \\
\text { competi- } \\
\text { tiva } \\
\text { (VRIO) }\end{array}$ & $\begin{array}{l}\text { Processo de formação da } \\
\text { base dos recursos } \\
\text { (BARNEY, 1986; DIER- } \\
\text { ICKX; COOL, 1989). }\end{array}$ \\
\hline \multirow{4}{*}{$\begin{array}{c}\text { Fase } 1 \\
(1973 \text { a } \\
\text { 1994): Casa } \\
\text { do Norte }\end{array}$} & \multirow{4}{*}{$\begin{array}{c}\text { Qualidade do } \\
\text { produto }\end{array}$} & \multirow{4}{*}{ Emergente } & Humanos & VCS* & \multirow{4}{*}{ Desenvolvido internamente } \\
\hline & & & Organizacionais & VCS* & \\
\hline & & & Reputacional & $\mathrm{VC}$ & \\
\hline & & & Relacional & VCS* & \\
\hline \multirow{6}{*}{$\begin{array}{c}\text { Fase } 2 \\
\text { (1995 a } \\
\text { 2004): É } \\
\text { um Restau- } \\
\text { rante ou um } \\
\text { Bar? }\end{array}$} & \multirow{3}{*}{$\begin{array}{c}\text { Qualidade do } \\
\text { produto }\end{array}$} & \multirow{6}{*}{ Emergente } & Humanos & VCS* & \multirow{6}{*}{ Desenvolvido internamente } \\
\hline & & & Organizacionais & VCS* & \\
\hline & & & Reputacional & $\mathrm{VC}$ & \\
\hline & \multirow{3}{*}{ Hospitalidade } & & Relacional & VCS* & \\
\hline & & & $\begin{array}{c}\text { Tecnológicos } \\
\text { Intangíveis }\end{array}$ & VCS* & \\
\hline & & & Físicos & $\mathrm{PC}$ & \\
\hline
\end{tabular}

(continua) 
Tourism in Analysis

Quadro 2 - Continuação

\begin{tabular}{|c|c|c|c|c|c|}
\hline \multirow{5}{*}{$\begin{array}{c}\text { Fase } 3 \\
\text { (2005 a } \\
\text { 2013): } \\
\text { Tomei caldo } \\
\text { de Mocotó } \\
\text { e fiquei } \\
\text { forte }\end{array}$} & $\begin{array}{l}\text { Qualidade do } \\
\text { produto }\end{array}$ & \multirow{5}{*}{$\begin{array}{l}\text { Emergente } \\
\text { e Planejado }\end{array}$} & Humanos & VCS* & $\begin{array}{l}\text { Adquirido e desenvolvido } \\
\text { internamente }\end{array}$ \\
\hline & Hospitalidade & & Organizacional & VCS* & \multirow{4}{*}{ Desenvolvido internamente } \\
\hline & $\begin{array}{c}\text { Contar uma } \\
\text { história - } \\
\text { Sertão }\end{array}$ & & Reputacional & VCS* & \\
\hline & \multirow[b]{2}{*}{$\begin{array}{l}\text { Tradição e } \\
\text { Vanguarda }\end{array}$} & & Relacional & $\mathrm{VCS}^{*}$ & \\
\hline & & & $\begin{array}{l}\text { Tecnológicos } \\
\text { Intangíveis e } \\
\text { Tangíveis }\end{array}$ & VCS* & \\
\hline
\end{tabular}

*Obs.: VCS - Vantagem Competitiva Sustentável. PC - Paridade Competitiva Fonte: Elaboração dos autores (2016)

Nessa época apesar do tamanho da empresa, a cultura, recurso organizacional intangível (BARNEY, 1991; GRANT; 1991: PIKE, ROOS, MARR, 2005), começou a ser delineada, no relato do chef: "somos uma empresa familiar e não conheço somente cada pessoa que está aqui e a história delas, como conheço cada tijolo que foi colocado nas duas casas". O recurso reputacional (BARNEY, 1991; GRANT; 1991: PIKE, ROOS, MARR, 2005) nessa fase se refere ao produto principal vendido que era o caldo de mocotó que fazia muito sucesso entre os clientes. Importante destacar a complementariedade entre os recursos humanos, o Sr. Zé Almeida e posteriormente o chef Rodrigo Oliveira, e os recursos reputacionais de marca, por exemplo, que corroboram os achados de Vomberg, Homburg e Bornemann (2014). Por fim, os recursos relacionais nessa fase se referem à rede de relacionamentos do Sr. Zé Almeida, com clientes e fornecedores e muitos deles ainda mantêm esta relação com o fundador da casa. Ao analisar o processo de desenvolvimento desses recursos pode-se inferir que todos os recursos foram desenvolvidos internamente, o que corrobora a teoria que afirma serem recursos intangíveis como a reputação que foi desenvolvida internamente (DIERICKX; COOL, 1989). Na segunda fase (1995-2004) da história do Mocotó os mesmos recursos se mantiveram e foram acrescentados os recursos físicos que na fase são representados exclusivamente pelo ambiente de serviço do restaurante capazes apenas de gerar paridade competitiva; e os recursos tecnológicos e de inovação, ambos intangíveis (GRANT, 1991; HALL, 1992) representados pela capacidade do chef Rodrigo Oliveira em criar e inovar. Nessa fase foram 
Tourism in Analysis

introduzidas as primeiras inovações no cardápio do Mocotó bem como realizadas as primeiras reformas no ambiente físico do restaurante.

A reputação do produto continuou a aumentar e a rede de relacionamento também cresceu, principalmente graças ao curso de gastronomia do chef. A cultura organizacional continuou a se formar e a entrada de Rodrigo na administração do restaurante foi essencial para a gestão de pessoas se tornar mais profissional, conforme a sua explicação: "tem 100 pessoas trabalhando, registradas, recebendo incentivo para crescer, estudar, ganhando salários acima da média do setor, com plano de carreira".

A análise dos dados permite afirmar que todos os recursos dessa fase também foram desenvolvidos internamente como resultado de um processo interno de criação fundamentada nas escolhas estratégicas do corpo gerencial (RUMELT, 1997). Por exemplo, o Mocotó utiliza uma estratégia de remuneração provavelmente não praticada em restaurantes que é a divisão por igual da taxa de serviço cobrada para todos os funcionários que recebem exatamente o mesmo valor da remuneração variável decorrente dessa taxa como afirma o gerente: "eu ganho a mesma coisa que o commin [...] é exatamente o mesmo valor, não tem pontuação". A estratégia do Mocotó nessa fase pode ser resumida na afirmação do chef: “A receita para manter uma casa por tanto tempo tem dois ingredientes principais: boa comida e hospitalidade". Nesse caso, a gestão de pessoas sustenta essas premissas.

Na terceira e última fase do restaurante (2005-2013), os recursos estratégicos necessários à consecução das estratégias adotadas permaneceram os mesmos e foram acrescidos recursos tecnológicos e de inovação tangíveis que são os direitos autorais e as marcas registradas. A capacidade de inovar e criar do chef teve como consequência algumas receitas que são copiadas em todo o país como os dadinhos de tapioca e o sorvete de rapadura. Devido às limitações de espaço apenas a última etapa do processo de desenvolvimento e/ou aquisição de recursos será demonstrada conforme Figura 2, que foi elaborada com o auxílio do software Atlas.ti. Nela estão retratadas as categorias de análise, a relação entre essas categorias bem como as evidências empíricas que suportam as categorias. 
Tourism in Analysis

Figura 2 - Processo de desenvolvimento e ou aquisição de recursos - Fase 3

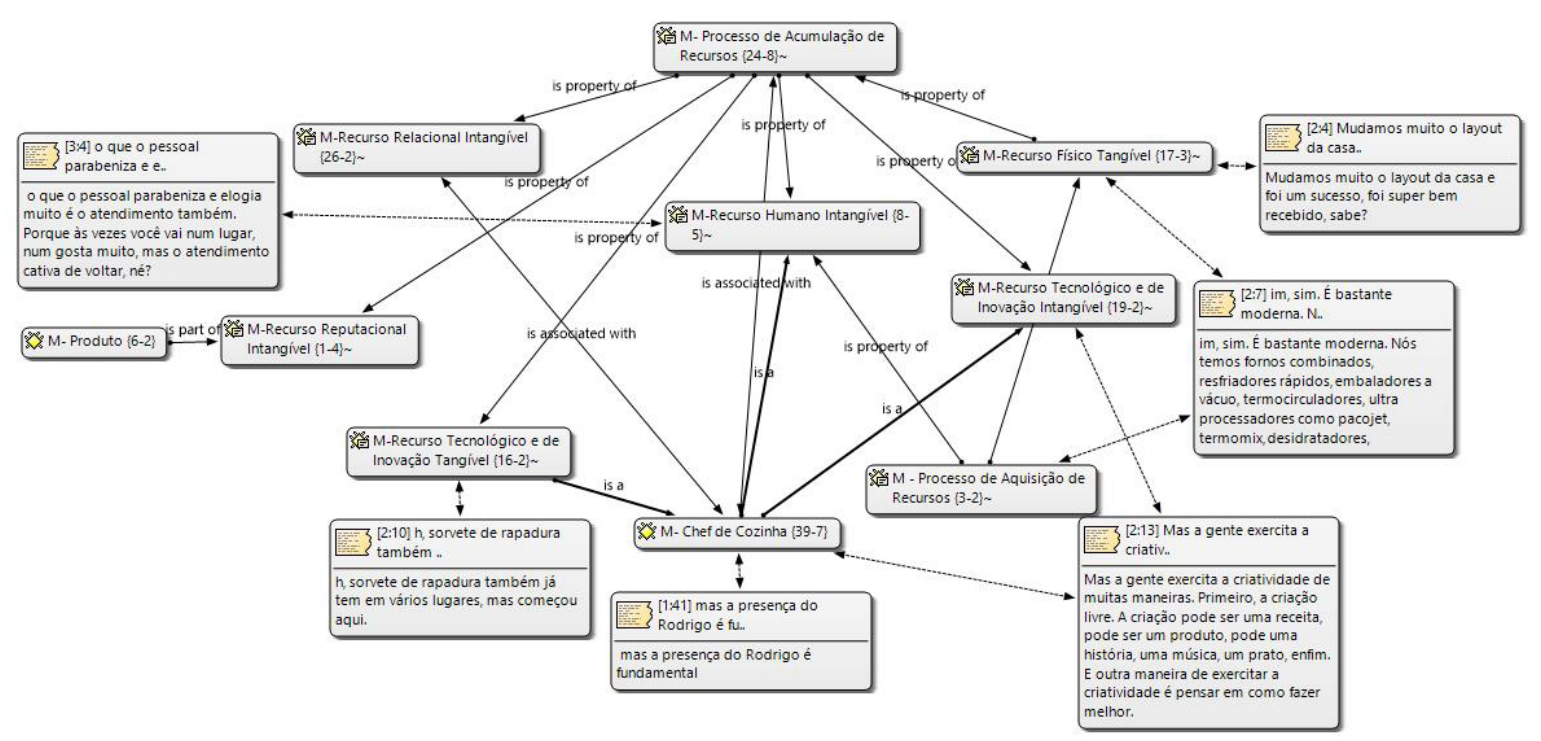

Fonte: Elaboração dos autores com Atlas.ti (2016)

Ao ambiente de serviço na categoria dos recursos físicos, nessa fase foram acrescentados também os equipamentos de cozinha. Atualmente a cozinha do Mocotó tem equipamentos de última geração como termocirculadores, Termomix, Pacojet, Sous Vide - equipamentos estes, em sua maioria, desenvolvidos na Espanha na década passada via parcerias entre chefs espanhóis e o governo. Outros equipamentos foram desenvolvidos no próprio Mocotó pelo chef, conforme esclarece Rodrigo: "um equipamento que a gente adaptou para o nosso uso de maneira inédita, aquecido a carvão, uma brasinha de carvão". Especificamente esse recurso foi desenvolvido internamente, mas também adquirido no mercado (BARNEY, 1986). Os recursos humanos que até então vinham sendo desenvolvidos internamente, até pela política de contratação do restaurante de selecionar as pessoas para os cargos mais baixos na hierarquia. Nessa fase percebe-se que o restaurante chama a atenção de estudantes formados em gastronomia que passaram a estagiar e posteriormente a serem contratados, evidenciando que esse recurso especificamente foi concomitante, por ser tanto adquirido quanto desenvolvido, conforme ressalta o chef:

E mais um terceiro mundo que nasceu do encontro desses dois mundos que você vai adorar. Os nossos meninos, vendo o desempenho e o que esses meninos traziam da faculdade, da universidade, começaram a cultivar a ideia de: "Poxa, 
Tourism in Analysis

será que eu podia?"... e vivendo ali, lado a lado com... “Eu posso fazer. Por que é que a gente... eu posso fazer também". Alguns foram primeiro em busca de supletivo para terminar só estudo básico e já estão agora estudando gastronomia.

Nessa última fase a cultura organizacional também aparece como um diferencial do Mocotó e inclui métodos de contratação - contratam apenas pessoas indicadas pelos funcionários; e todos iniciam pelo menor cargo na hierarquia do restaurante; métodos de promoção - valorizar as pessoas da casa; e métodos de premiação - dividem os $10 \%$ igualmente entre todos os funcionários. Por fim, a rede de relacionamento, especificamente do chef, na última fase também aumentou e passou a ser formada por fornecedores com quem o chef inovou desenvolvendo produtos como uma fritadeira. Essa relação entre inovação em empresas familiares e as redes de relacionamento corroboram os achados de DeMassis et al. (2015). Ademais a rede de relacionamento foi formada também por chefs estrelados nacionais como Alex Atala, Laurent Suaudeau e Jefferson Rueda, assim como internacionais, a exemplo de Gastón Acurio, Ferran Adrià e os irmãos Rocca, com representantes da mídia especializada e de restaurantes da região.

\section{Considerações finais}

O caso escolhido para a pesquisa foi o Restaurante Mocotó, listado em $16^{\circ}$ lugar na publicação inglesa The Restaurants, considerada um guia de vanguarda da gastronomia. A história da empresa, fundada em 1973, foi dividida em três fases e em cada uma das fases foram identificadas as estratégias adotadas, os recursos necessários para a consecução das estratégias bem como identificado o processo de acumulação desses recursos.

As estratégias adotadas pela empresa se basearam na qualidade do produto, na hospitalidade, em contar uma história e na tradição aliada à vanguarda. É interessante refletir sobre essas estratégias, no caso da hospitalidade foi destacada e aponta como um diferencial na empresa. O bem receber e acolher sempre foi uma marca da personalidade do fundador, Sr. Zé Almeida, do seu filho Rodrigo e está presente também na cultura organizacional da empresa. Em tempos de fastfood, ser bem acolhido desponta como um diferencial.

Pelas características da oferta os restaurantes gastronômicos proporcionam muito mais do que alimentos e bebidas, pois são empresas que vendem uma experiência de consumo. 
Tourism in Analysis

Portanto uma boa história bem contada deve provocar uma poderosa reação emocional e desenhar uma experiência (BROWN, 2010).

No caso do Mocotó, a história contada é a história do Sertão e do Sr. Zé Almeida. Essa história é apresentada por meio do cardápio, do ambiente, do modo de receber e servir às pessoas, mas nunca de um modo caricato e com vistas a exaltar o que o sertão e o sertanejo têm de diferencial. Para contar essa história é necessário ter consistência, portanto algumas estratégias operacionais usadas em restaurantes de vanguarda não se aplicam ao Mocotó como a utilização de técnicas da cozinha molecular e estratégia de vendas como o Menu Degustação.

Por fim a estratégia de tradição e a vanguarda que aparentemente parecem contraditórias fazem do Mocotó uma experiência única e consiste em adotar uma abordagem vanguardista da tradição, ou seja, empregar técnicas modernas na execução de receitas tradicionais como a fritura com temperatura controlada do torresmo ou o cozimento da carne-de-sol em sous-vide. No Mocotó as técnicas (modernas) estão sempre a serviço da criatividade e nunca aparecem como mais importante do que os produtos, tanto que essas técnicas não são descritas no cardápio.

Para implementaras estratégias, os recursos estratégicos identificados foram a cultura organizacional, os recursos humanos e o chef. Este merece destaque, já que foi graças a sua rede de relacionamento, sua capacidade de criação e inovação e à reputação alcançada pelo seu trabalho é que o Mocotó se tornou um restaurante premiado. Esses recursos foram desenvolvidos ao longo da história da empresa e nesse caso, os achados corroboram os argumentos de Dierickx e Cool (1989) de que os recursos estratégicos são intangíveis e desenvolvidos internamente. Por fim, os únicos recursos que foram adquiridos no mercado e concomitantemente desenvolvidos internamente foram alguns dos equipamentos da cozinha moderna e os recursos humanos da cozinha.

\section{Referências}

ALVAREZ, S.A.; BUSENITZ, L. W. The entrepreneurship of resource-based theory. Journal of Management, v. 27, n. 6, p. 755-775, 2001.

AMIT, R.; SCHOEMAKER, P. J. H. Strategic assets and organizational rent. Strategic Management Journal, v. 14, n. 1, p. 33-46, 1993. 
Tourism in Analysis

AUTY, S. Consumer choice and segmentation in the restaurant industry. The Service Industries Journal, v. 12, p. 324-339, 1992.

BARBOSA, M. L. A. Crítica Gastronômica. Disponível em: <http://www.bemtemperado.com.br/ detalheartigo.php?CodArtigos=6>. Acesso em: 4 maio 2011.

BARDIN, L. Análise de conteúdo. São Paulo: Edições 70, 2011.

BARNEY, J. B. Firm resources and sustained competitive advantage. Journal of Management, v. 17, n. 1, p. 99-120, 1991.

.Gaining and sustaining competitive advantage. 3. ed. New Jersey: Prentice-Hall, 2002.

. Strategic factor markets: expectations, luck, and business strategy. Management Science, v. 32, n. 10, p. 1231-1241, 1986.

BARNEY, J. B.; WRIGHT, M.; KETCHEN, D. J. The resource-based view of the firm: ten years after 1991. Journal of Management, v. 27, n. 6, p. 625-641, 2001.

BAUER, M. W.; GASKELL, G. Pesquisa qualitativa com texto, imagem e som: um manual prático. 4. ed. Petrópolis: Vozes, 2002.

BINDER, M. P. Recursos e competências sob turbulência: estudo longitudinal de três empresas aéreas. 2006. 343f. Tese (Doutorado em Administração) - Programa de Pós-Graduação em Administração, Fundação Getúlio Vargas, São Paulo, 2006.

BRITO, L. A. L.; VASCONCELOS, F. C. A heterogeneidade do desempenho, suas causas e o conceito de vantagem competitiva: proposta de uma métrica. Revista de Administração Contemporânea - RAC, p.107-129, 2004. Edição Especial.

BROWN, T. Design thinking: uma metodologia poderosa para decretar o fim das velhas ideias. Rio de Janeiro: Elsevier, 2010.

CARNEIRO, J. M. T.; CAVALCANTI, M. A. F. D.; SILVA, J. F. Os determinantes da sustentabilidade da vantagem competitiva na visão resource-based. In: ENCONTRO DA ANPAD, 23., 1999, Foz do Iguaçu. Anais... Foz do Iguaçu: EnAnpad, 1999.

CRESWELL, J. W. Projeto de pesquisa: métodos qualitativo, quantitativo e misto. 3. ed. Porto Alegre: Artmed/Bookman, 2010.

.Qualitative inquiry and research design: choosing among five approaches. 2. ed. Thousand Oaks: Sage, 2007.DE MASSIS, A. et al. Product innovation in family versus nonfamily: an exploratory analysis. Journal of Small Business Management, v. 53, n. 1, p. 1-36, 2015. 
Tourism in Analysis

DE WIT, B.; MEYER, R. Strategy: process, content, context. 3. ed. London: Thomson, 2004.

DIERICKX, I.; COOL, K. Asset stock accumulation and sustainability of competitive advantage. Management Science, v.35, n. 12, p. 1504-1513, 1989.

EISENHARDT, K.; SCHOONHOVEN, K. Organizational growth: linking founding team, strategy, environment, and growth among U.S. semiconductor ventures. Administrative Science Quarterly, v. 35, n. 3, p. 504-529, 1990.

FERREIRA, M. R.; VALDUGA, V.; BAHL, M. Baixa gastronomia: caracterização e aproximações teórico-conceituais. Turismo em Análise, v. 27, n. 1, abril 2016.

FLICK, U. Introdução à pesquisa qualitativa. 3. ed. Porto Alegre: Artmed/Bookman, 2009.

FONSECA, M. T. Tecnologias gerenciais de restaurantes. São Paulo: Senac, 2000.

GRANT, R. M. The resource-based theory of competitive advantage: implications for strategy formulation. California Management Review, v. 33, n. 3, p. 114-135, 1991.

GUSTAFSSON, I.B. et al. The five aspects meal model: a tool for developing meal service in restaurants. Journal of Food Service, v. 17, n. 2, p. 84-93, 2006.

GODOY, A, S. Pesquisa qualitativa: tipos fundamentais. Revista de Administração de Empresas $R A E$, v. 35, n. 3, p. 20-29, 1995.

HANSEN, K. V.; JENSEN, O.; GUSTAFSSON, I. B. The meal experience of a la carte restaurant customers. Scandinavian Journal of Hospitality and Tourism, v. 5, n. 2, p. 135-151, 2005.

HELFAT, C. E.; PETERAF, M. A. The dynamic resource-based view: capability lifecycle. Strategic Management Journal, v. 24, p. 997-1010, 2003.

HETZEL, P. Vers une approche experientielle de la haute cuisine française: lorsque marketing rime avec construction du sens. Revue Française du Marketing, n. 196, p. 67, 2004.

HITT, M. A.; IRELAND, R. D.; HOSKISSON, R. E. Administração estratégica: competitividade e globalização. São Paulo: Pioneira Thomson Learning, 2003.

JOHNS, N.; KIVELA, J. J. Perceptions of the first time restaurant customer. Food Service Technology, v. 1, p.5-11, 2001.

MARITAN, C. A.; PETERAF, M. A. Building a bridge between resource acquisition and resource accumulation. Journal of Management, v. 37, n.5, p. 1374-1389, 2011. 
Tourism in Analysis

MENDONÇA, J. R.; BARBOSA, M. L. A.; DURÃO, A. F. Fotografias como um recurso de pesquisa em marketing: o uso de métodos visuais no estudo de organizações de serviços. Revista de Administração Contemporânea, v. 11, n. 3, jul./set. 2007.

MENDONÇA, J. R.; MELO, R. C. B.; PADILHA, M. A. S. O Atlas.ti para a análise de fotos na pesquisa qualitativa: uma discussão ilustrada sobre métodos visuais na educação. In: CONGRESSO NACIONAL DE EDUCAÇÃO, 10., 2011, Curitiba. Anais... Curitiba: EDUCERE, 2011.

MERRIAM, S. B. Qualitative research and case study applications in education. San Francisco: Jossey-Bass, 1998.

MILLER, D.; MINICHILLI, A.; CORBETTA, G. Is family leadership always beneficial? Strategic Management Journal, v. 34, n. 5, p. 553-571, 2013.

MILLER, D.; SHAMSIE, J. The resource-based view of the firm in two environments: the Hollywood Film Studios from 1936 to 1965. The Academy of Management Journal, v. 39, n. 3, p. 519-543, 1996.

MINTZBERG, H. Patterns in strategy formation. Management Science, v. 24, n. 9, p. 934-948, 1978. . Strategy-making in three modes. California Management Review, v. 16, n. 2, p. 44-53, 1973.

MOZZATO, A. R. Análise de conteúdo como técnica de análise de dados qualitativos no campo da administração: potencial e desafios. In: ENCONTRO ANUAL DA ANPAD, 34., 2010, Rio de Janeiro. Anais... Rio de Janeiro: ANPAD, 2010.

PATTON, M. Q. Qualitative research and evaluation methods. Thousand Oaks: Sage, 2001.

PENROSE, E. A teoria do crescimento da firma. Campinas: Unicamp, 2006.

PETERAF, M. A. The cornerstones of competitive advantage: a resource-based view. Strategic Management Journal, v. 14, n. 3, p. 179-188, 1993.

PETTIGREW, A. M. Context and action in transformation of the firm. Journal of Management Studies, v. 24, n. 6, p. 649-670, 1987.

. Longitudinal field research on change: theory and practice. Organization Science, v. 1, n. 3, p. 267-292, 1990.

.The character and significance of strategy process research. Strategic Management Journal, v. 13, p. 5-16, 1992. Número Especial.

PETTIGREW, A. M.; WOODMAN, R. W.; CAMERON, K. S. Studying organizational change and development: challenges for future research. The Academy of Management Journal, v. 44, n.4, p. 697-713, 2001. 
Tourism in Analysis

PIKE, S.; ROOS, G.; MARR, B. Strategic management of intangible assets and value drivers in R\&D organizations. $R \& D$ Management, Oxford, v. 35, n. 2, p. 111-124, 2005.

PRAHALAD, C. K.; HAMEL, G. The core competence of the corporation. Harvard Business Review, p. 79-91, maio-jun. 1990.

PRIEM, R. L.; BUTLER, J. E. Is the resource-based "view" a useful perspective for strategic management research? The Academy of Management Review, v. 26, n. 1, p. 22-40, 2001.

RONDA-PUPO, G. A.; GUERRAS-MARTIN, L. A. Dynamics of the evolution of the strategy concept 1962-2008: a co-word analysis. Strategic Management Journal, v. 33, n. 2, p. 162-188, 2012.

RUMELT, R. P. Towards a strategic theory of the firm. In: FOSS, N. J. (Ed.). Resources, firms, and strategies: a reader in the resource-based perspective. Oxford: Oxford University Press, 1997. p. 131-145.

SLOAN, D. Gastronomia, restaurante e comportamento do consumidor. São Paulo: Manole, 2005.

SURLEMONT, B. et al. Revenue models in haute cuisine: an exploratory analysis. International Journal of Contemporary Hospitality Management, v. 17, n. 4, p. 286-301, 2005.

SURLEMONT, B.; JOHNSON, C. The role of guides in artistic industries: the special case of the "star system" in the haute-cuisine sector. Managing Service Quality, v. 15, n. 6, p. 577-590, 2005.

TAYLOR, S. J.; BOGDAN, R. Introduction to qualitative research methods: the search for meanings. 2. ed. New York: John Wiley \& Sons, 1984. p. 123-145.

TEIXEIRA, A. K. G; BARBOSA, M. L. A. O sistema de oferta de restaurantes de alta gastronomia: uma perspectiva sensorial das experiências de consumo. In: ENCONTRO DA ASSOCIAÇÃO NACIONAL DE PÓS-GRADUAÇÃO E PESQUISA EM ADMINISTRAÇÃO, 32., 2008, Rio de Janeiro. Anais... Rio de Janeiro: ANPAD, 2008.

VOMBERG, A.; HOMBURG, C.; BORNEMANN, T. Talented people and strong brands: the contribution of human capital and brand equity to firm value. Strategic Management Journal, v. 36, n. 13, p. 2122-2131, 2015.

WERNERFELT, B. A resource-based view of the firm. Strategic Management Journal, v. 5, n. 2, p. 171-180, 1984.

YIN, R. K. Estudo de caso: planejamento e métodos. 4. ed. Porto Alegre: Bookman, 2010.

ZANETI, T. B. Das panelas das nossas avós aos restaurantes de alta gastronomia: os processos sociais de valorização de produtos agroalimentares tradicionais. 2012. 182f. Dissertação (Mestrado em Agronegócios) - Programa de Pós-Graduação em Agronegócios, Universidade de Brasília, Brasília, 2012. 
Tourism in Analysis

695

ZOTT, C. Dynamic capabilities and the emergence of intraindustry differential firm performance: insights from a simulation study. Strategic Management Journal, v. 24, n. 2, p. 97-125, 2003.

Recebido em: 21/06/2016 (1 ${ }^{\mathrm{a}}$ versão) $19 / 08 / 2016$ ( $2^{\mathrm{a}}$ versão)

Aprovado em: 06/09/2016 